\title{
Chronic-Stress-Induced Behavioral Changes Associated with Subregion-Selective Serotonin Cell Death in the Dorsal Raphe
}

\author{
Reka Natarajan, ${ }^{1}$ Laura Forrester, ${ }^{2}{ }^{\oplus}$ Nicolas L. Chiaia, ${ }^{2}$ and Bryan K. Yamamoto ${ }^{1}$ \\ ${ }^{1}$ Department of Pharmacology and Toxicology, Indiana University School of Medicine, Indianapolis, Indiana 46202, and ${ }^{2}$ Department of Neurosciences, \\ University of Toledo College of Medicine, Toledo, Ohio 43614
}

The current study examined the neurochemical mechanisms and neuroanatomical changes underlying coexisting behavioral effects associated with chronic-stress-induced alterations in serotonin (5HT) neurons. Chronic unpredictable stress (CUS) to adult male rats produced depression-like changes with cognitive dysfunction and selective cell death in the interfascicular nucleus of the dorsal raphe (DRif), resulting in decreased 5HTergic innervation of medial prefrontal cortex (mPFC). Twenty-one days of CUS decreased basal plasma levels of corticosterone and produced a shorter latency to immobility and longer durations of immobility in the force-swim test that persisted for 1 month after CUS. Deficits in acquisition, recall, perseveration, and reversal learning were evident 1 month after CUS. MK801 treatment during CUS blocked the changes in the forced-swim test and deficits in memory recall. These behavioral changes were associated with terminal deoxynucleotidyl transferase dUTP nick end labeling (TUNEL)-positive soma and the eventual loss of 5HT neurons in the DRif and its projections to the MPFC as evidenced by fewer labeled cells in the DRif after retrograde tracer injections into the mPFC of stressed rats. Similar to the effects of MK801 on behavior, MK801 pretreatment during stress blocked the CUS-induced decreases in 5HT soma within the DRif and its projections to the mPFC. Finally, the depression-like behaviors were blocked by acute injection of the 5HT2A/C agonist (-)-2,5-dimethoxy-4-iodoamphetamine hydrochloride into the mPFC before forced-swim testing. These results identify a cause and mechanism of 5HTergic dysfunction of the MPFC and associated mood and cognitive behaviors.

Key words: chronic stress; frontal cortex; raphe; serotonin

Significance Statement

Chronic stress causes persistent mood and cognitive changes typically associated with dysregulated serotonin (5HT) transmission in the medial prefrontal cortex (mPFC), but the cause of this dysregulation is unknown. Prior studies have focused on 5HTergic terminals in this region, but this study shows that chronic stress causes NMDA-receptor-dependent and subregion-specific cell death of 5HT neurons in the dorsal raphe. The consequent decreased 5HT innervation of the mPFC was associated with mood and cognitive changes that persisted long after the termination of stress. These findings identify a mechanism of subregion-selective death of 5HT neurons in the dorsal raphe, a defined neuroanatomical pathway, and a behavioral phenotype that mirror stressassociated diseases such as major depressive disorder.

\section{Introduction}

Stress increases risk for development of diseases in which lasting mood and cognitive deficits are observed (Marshall et al., 1996).

Received Dec. 9, 2016; revised April 25, 2017; accepted May 16, 2017.

Author contributions: R.N., N.L.C., and B.K.Y. designed research; R.N., L.F., and N.L.C. performed research; R.N. and B.K.Y. analyzed data; R.N. and B.K.Y. wrote the paper.

This work was supported by the National Institutes of Health (Grant DA007606).

The authors declare no competing financial interests.

Correspondence should be addressed to Bryan Yamamoto, Department of Pharmacology and Toxicology, Indiana University School of Medicine, 635 Barnhill Drive, MS A401, Indianapolis, IN 46202. E-mail: brkyama@iu.edu.

DOI:10.1523/JNEUROSCI.3781-16.2017

Copyright $\odot 2017$ the authors $\quad 0270-6474 / 17 / 376214-10 \$ 15.00 / 0$
An animal model used to study stress induced behavioral changes is the chronic unpredictable stress (CUS) paradigm, which approximates the psychological aspects of the chronicity, unpredictability, and uncontrollability of everyday stressors experienced by humans. This paradigm has been used in an attempt to model stress-related disorders such as depression and cognitive dysfunction (Demitrack et al., 1991).

CUS-induced neuropsychopathologies have been attributed typically to dysfunctions of the brain serotonin (5HT) system characterized by $5 \mathrm{HT}$-induced dysregulation of the hypothalamus-pituitary-adrenal stress axis, desensitized 5HT receptors, and decreased neuronal firing (Demitrack et al., 1991; van Riel et 
al., 2003; Bondi et al., 2008; Bambico et al., 2009). 5HT innervations and terminals within the medial prefrontal cortex (mPFC) in particular have received the most attention because a key feature of patients with major depressive disorder is decreased 5HT transporter binding and 5HT turnover in the mPFC (Mann, 1999; Mann et al., 2000). However, few studies have examined the source of $5 \mathrm{HT}$ dysfunction in these behaviors.

A major source of $5 \mathrm{HT}$ innervations of the $\mathrm{mPFC}$ and throughout the forebrain is derived from the dorsal raphe nucleus (DRN) (Hale and Lowry, 2011). Stressors can activate distinct subregions of the DRN differentially (Grahn et al., 1999) (Hale and Lowry, 2011), such as the interfascicular DRN (DRif), which projects to mPFC (Littrell, 2012; Paul and Lowry, 2013). Interestingly, 5HT soma in the DRif have unique morphological, electrophysiological, and receptor profiles that could render it selectively sensitive to stress (Ahima and Harlan, 1990; Valentino et al., 2010; Hale and Lowry, 2011; Lukkes et al., 2011; SoizaReilly and Commons, 2011). Furthermore, no studies have investigated whether chronic stress exposure is linked to a loss of 5HT soma within the DRN or the DRif specifically that is associated with long-term changes in 5HT- and mPFC-dependent mood and cognitive function.

The mPFC contains multiple neurotransmitters in addition to its 5HTergic innervation, including glutamate and GABA, and alterations in their functions affect $\mathrm{MPFC}$-dependent behaviors (Drevets et al., 2008). Few studies, however, have examined the role of the DRN and its projections to the mPFC in mood and cognitive behavior and the role of the NMDA receptor in modulating changes in these projections.

Based on the afferents and efferents of the DRif and the involvement of $5 \mathrm{HT}$ in mediating stress-related psychopathologies, we tested the hypothesis that exposure of rats to CUS is associated with persistent depression-like changes and cognitive deficits. Furthermore, we investigated the possibility that these changes are associated with cell death of 5HT soma specifically in the DRif, which is produced by activation of the NMDA receptor to cause a decreased 5HTergic innervation of the mPFC.

\section{Materials and Methods}

Animals. All experiments were conducted in accordance with the National Institutes of Health's Guide for the Care and Use of Laboratory Animals and were approved by the Indiana University Institutional Animal Care and Use Committee. Adult male Sprague Dawley rats (175-200 g, $n=360$; Harlan Laboratories) were initially housed two per cage under a $12 \mathrm{~h}$ light/dark (6:00 A.M. lights on/6:00 P.M. lights off) cycle in a temperature- and humidity-controlled environment. Rats had ad libitum access to food and water and were allowed to acclimate to the housing facility for $4 \mathrm{~d}$ before experimentation began.

CUS paradigm. Rats were either handled daily (NoStress) or exposed to the CUS paradigm (Stress) consisting of $21 \mathrm{~d}$ of twice daily exposure to mild stressors. The CUS paradigm was used to prevent habituation and adaptation to stress and attempted to model unanticipated stressful experiences that occur in humans (Katz et al., 1981; Willner et al., 1992). Other than the days indicated below, all rats were on a $12 \mathrm{~h}$ light/dark cycle. The stress schedule was as follows: day $1: 60 \mathrm{~min} 4^{\circ} \mathrm{C}$ cold room $(10: 00 \mathrm{~h})$ and $60 \mathrm{~min}$ restraint $(14: 00 \mathrm{~h})$; day $2: 3 \mathrm{~h}$ lights off $(11: 00 \mathrm{~h})$ and lights on overnight $(18: 00 \mathrm{~h})$; day $3: 3 \mathrm{~min}$ swim $(11: 30 \mathrm{~h})$ and food and water deprivation overnight (17:00-8:00 h); day 4: 60 min wet bedding $(9: 30 \mathrm{~h})$ and $60 \mathrm{~min}$ social stress where cage partners were switched $(15: 00 \mathrm{~h})$; day 5: $60 \mathrm{~min}$ restraint $(11: 00 \mathrm{~h})$ and $90 \mathrm{~min}$ cage agitation in an orbital shaker $(14: 30 \mathrm{~h})$; day $6: 3 \mathrm{~h}$ lights off $(10: 00 \mathrm{~h})$ and isolation overnight (17:00-8: $00 \mathrm{~h})$; day 7: $3 \mathrm{~min} \operatorname{swim}(10: 00 \mathrm{~h})$ and $60 \mathrm{~min} 4^{\circ} \mathrm{C}$ cold room (13:00 h); day 8: 60 min wet bedding $(9: 30 \mathrm{~h})$ and 60 min restraint (16:00 h); day 9: 30 min cage agitation $(11: 30 \mathrm{~h})$ and $60 \mathrm{~min}$ social stress $(14: 30 \mathrm{~h})$; day $10: 60 \mathrm{~min} 4^{\circ} \mathrm{C}$ cold room $(9: 30 \mathrm{~h})$ and $60 \mathrm{~min}$ restraint
(15:30 h); day 11:3 h lights off (10:30 h) and lights on overnight (18:00 h); day 12: $3 \mathrm{~min}$ swim $(10: 00 \mathrm{~h})$ and food and water deprivation overnight $(17: 30-8: 00 \mathrm{~h})$; day $13: 90 \mathrm{~min}$ wet bed $(10: 00 \mathrm{~h})$ and $30 \mathrm{~min}$ social stress $(14: 00 \mathrm{~h})$; day 14: $60 \mathrm{~min}$ restraint $(11: 30 \mathrm{~h})$ and $60 \mathrm{~min}$ cage agitation $(15: 30 \mathrm{~h})$; day $15: 3 \mathrm{~h}$ lights off $(9: 30 \mathrm{~h})$ and isolation overnight (17:00 8:00 h); day $16: 3 \mathrm{~min}$ swim $(10: 30 \mathrm{~h})$ and $60 \mathrm{~min} 4^{\circ} \mathrm{C}$ cold room $(13: 30$ $\mathrm{h})$; day $17: 30 \mathrm{~min}$ wet bedding $(11: 30 \mathrm{~h})$ and food and water deprivation overnight (18:00-8:00 h); day 18: 90 min social stress $(11: 00 \mathrm{~h})$ and 30 min cage agitation $(15: 00 \mathrm{~h})$; day 19: $3 \mathrm{~h}$ lights off $(9: 00 \mathrm{~h})$ and $60 \mathrm{~min}$ restraint (14:00 h); day 20:3 min swim (11:00 h) and lights on overnight $(17: 30 \mathrm{~h})$; and day $21: 30 \mathrm{~min}$ wet bedding $(10: 00 \mathrm{~h})$ and $60 \mathrm{~min}$ social stress (13:30 h).

Corticosterone assay. Rats were decapitated and trunk blood was collected in the morning $(08: 00 \mathrm{~h})$ after the last stressor. Blood was centrifuged for $15 \mathrm{~min}$ at 800 relative centrifugal force (RCF) at $4^{\circ} \mathrm{C}$. The supernatant was transferred into a $1 \mathrm{ml}$ tube and centrifuged for $7 \mathrm{~min}$ at $800 \mathrm{RCF}$ at $4^{\circ} \mathrm{C}$. The serum was then assayed for corticosterone (CORT) levels (Corticosterone EIA kit, K014-H1; Arbor Assays). Briefly, $5 \mu \mathrm{l}$ of the serum sample and dissociation reagent in $490 \mu \mathrm{l}$ of assay buffer was vortexed. This sample mixture $(50 \mu \mathrm{l})$ or standards were added to the wells of the plate in triplicate, along with $75 \mu \mathrm{l}$ of assay buffer, $25 \mu \mathrm{l}$ of CORT conjugate, and antibody, and incubated at room temperature for $1 \mathrm{~h}$ on a shaker. The wells of the plate were then aspirated and washed in $300 \mu \mathrm{l}$ of wash buffer. $3,3^{\prime}, 5,5^{\prime}$-tetramethylbenzidine substrate $(100 \mu \mathrm{l})$ was added to the wells and incubated for $30 \mathrm{~min}$ at room temperature, followed by $50 \mu \mathrm{l}$ of the stop solution. The plate was then transferred to a spectrophotometer and the optical density at $450 \mathrm{~nm}$ of each well was recorded.

Drug treatments. MK801 (0.3 mg/kg, i.p.; catalog \#0924; R\&D Systems) was dissolved in $0.9 \% \mathrm{NaCl}$ (saline) and injected intraperitoneally $15 \mathrm{~min}$ before each stressor. This dose of MK801 is not neurotoxic, does not affect locomotor activity (Ikonomidou et al., 2000; Popke et al., 2002), and has been shown to reverse stress-induced anhedonia (Papp and Moryl, 1994).

Forced-swim test. The forced-swim test was conducted as described previously (Porsolt et al., 1977) with minor modifications. Rats underwent a forced swim pretest $3 \mathrm{~d}$ after CUS and again at 1 month after CUS. The forced-swim tests were performed for a duration of $15 \mathrm{~min}$ rather than the 3 min swim during the CUS exposure procedure to measure multiple aspects of depressive-like behavior such as latency to immobility and duration of immobility. The longer duration of testing provides more accurate measure of changes in these behaviors that may not be apparent in a shorter $3 \mathrm{~min}$ test. The rats were placed individually in a transparent chamber $(11$ " w $\times 8$ " $1 \times 22$ " $\mathrm{h})$ and allowed to swim for 15 min. Forced-swim testing was conducted the following day. The rats were once again placed in the swim chamber and swim behavior was video recorded for $10 \mathrm{~min}$. The latency to immobile behavior and the duration of time spent exhibiting immobile behavior was analyzed by a trained observer who was blinded to the treatment conditions.

Barnes maze. A separate group of rats were trained and tested on the Barnes maze (Barnes, 1979) 1 month after termination of CUS exposure. The Barnes maze is composed of a white circular disc that has 18 holes along the perimeter. The hole at the 2:00 position contained a dark goal box underneath it that the rat can enter to escape the brightly lit, exposed surface of the maze. Proximal and distal visual cues were provided around the maze to help the rat orient spatially and enable it to locate the goal box. Rats underwent Barnes maze acquisition training once daily for $5 \mathrm{~d}$, followed by a $2 \mathrm{~d}$ break during which they remained in the home cage. They were then tested the next day for memory recall function. For the following $5 \mathrm{~d}$, rats were overtrained to reach the goal box in $<15$ s by using an aversive auditory cue. The next day, a probe trial was conducted without any goal box placed in the maze and the time spent in the quadrant containing the goal box was noted as an indicator of perseverative behavior. The next day, the goal box was placed back in the 2:00 position and the rats were once again tested in the maze. The following day, the goal box was moved to the 5:00 position and the latency to find the goal box in the new location was noted to indicate cognitive flexibility and reversal learning. 
Immunofluorescence. One week after the last stressor, rats were anesthetized and $100 \mathrm{ml}$ of $0.1 \mathrm{M}$ PBS followed by $400 \mathrm{ml}$ of $4 \%$ paraformaldehyde (PFA) was perfused intracardially. Brains were removed and immersed in 4\% PFA overnight and cryoprotected by serial overnight immersion in $10 \%$ and $20 \%$ glycerol, after which they were flash-frozen in cooled isopentane solution. Brains were then sectioned using a cryostat. Serial slices ( $25 \mu \mathrm{m}$ thick) were taken through the DRN between -7.8 and -8.2 from bregma and 3 slices, each $125 \mu \mathrm{m}$ apart, per rat were immunolabeled and imaged by confocal microscopy for analysis.

Slices were mounted onto subbed slides and stored at $-20^{\circ} \mathrm{C}$. To visualize $5 \mathrm{HT}$ cells in the DRN, sections were double labeled for NeuN, a neuronal marker and tryptophan hydroxylase (TPH), the rate-limiting enzyme in the synthesis of 5HT. Slides were submerged in $10 \mathrm{~mm}$ citrate buffer and heated to $80^{\circ} \mathrm{C}$ for $15 \mathrm{~min}$ for antigen retrieval, washed in $0.1 \mathrm{M}$ PBS, blocked with $10 \%$ normal goat serum, and incubated overnight with $\mathrm{Ms} \times$ NeuN antibodies (1:1000, catalog \#MAB377, RRID: AB_ 2298772; Millipore) and Rb X TPH (1:1000, catalog \#NB100-74555, RRID: AB_1049988; Novus Biologicals). The following day, appropriate Alexa Fluor-conjugated secondary antibodies were applied for $1 \mathrm{~h}$ and the sections were washed and then coverslipped with Fluoromount-G (catalog \#17984; Fisher Scientific). Confocal microscopy and ImageJ software were used to visualize cell bodies with colocalized NeuN and TPH staining in the DRN. All cell counts were conducted by an observer blinded to the treatment conditions. Cell counts were taken from each of 3 slices over the range of the DRN between -7.8 and -8.2 from bregma. The cell counts were averaged across the three slices and the average was recorded for each rat.

TUNEL assay. Sections were washed in $0.1 \mathrm{~m}$ PBS and the assay performed per directions provided by the In Situ Cell Death Detection Fluorescein Kit from Roche (catalog \#11684795910). Briefly, $50 \mu$ l of the enzyme solution was added to $450 \mu \mathrm{l}$ of label solution. This mixture was applied to each of 3 tissue sections $(25 \mu \mathrm{m})$ that were taken every $125 \mu \mathrm{m}$ between -7.8 and -8.2 bregma through the DRN. Sections were incubated in TUNEL reaction mixture for $1 \mathrm{~h}$ at $37^{\circ} \mathrm{C}$ in a humidified chamber. Slides were washed in $0.1 \mathrm{M}$ PBS 3 times for $5 \mathrm{~min}$ and incubated with $\mathrm{Rb} \times \mathrm{TPH}$ and treated as described in the "Immunofluorescence" section above. Sections $(25 \mu \mathrm{m})$ were imaged using confocal microscopy. The intensity of TUNEL was dependent on the extent of active apoptosis and the stage of apoptosis within the cell. Cells of the DRif that were positive for TPH and TUNEL were counted from each of 3 different slices over the range of -7.8 to -8.2 from bregma. The ratio of TUNEL to TPH was obtained for each section and the average of the three sections was recorded for each rat by an observer blinded to the treatment condition.

Retrograde tracer surgery. Five days after the last stressor, rats were anesthetized with ketamine ( $75 \mathrm{mg} / \mathrm{kg}$, i.p.) and xylazine ( $5 \mathrm{mg} / \mathrm{kg}$, i.p.) and prepared for stereotaxic surgery. The retrograde tracer TrueBlue (0.6 $\mu \mathrm{l}$ of $2.5 \%$ ) (1,2 bis [5-Amidino-2benzofuranyl ethylene] Diaceturate salt, catalog \#T5891; Sigma-Aldrich) was pressure injected through a glass pipette stereotaxically positioned bilaterally into the $\mathrm{mPFC}(2.7 \mathrm{~mm}$ bregma, $0.5 \mathrm{~mm}$ lateral, $4 \mathrm{~mm}$ ventral). Two days after TrueBlue injection, $0.1 \mathrm{~m}$ PBS and 4\% PFA were perfused as described above. Brains were removed, cryoprotected, and sectioned through the rostrocaudal extent of the mPFC to verify tracer localization and diffusion from the site of injection. Each of 3 sections $(25 \mu \mathrm{m})$ collected every $125 \mu \mathrm{m}$ were representative of the rostral, middle, and caudal DRN between -7.8 and -8.2 from bregma. TrueBlue-positive cells of each section were imaged using confocal microscopy and visualized using ImageJ software. Cells containing the tracer in the DRif examined over three sections within the extent of the DRN were counted by an observer blinded to the treatment condition.

Bilateral cannula implantation surgery. On day 19 of CUS, rats were anesthetized with ketamine ( $75 \mathrm{mg} / \mathrm{kg}$, i.p.) and xylazine ( $5 \mathrm{mg} / \mathrm{kg}$, i.p.) and secured into a stereotaxic apparatus. Bilateral guide cannulae (26 gauge stainless steel) were implanted above the mPFC (2.7 mm bregma, $0.5 \mathrm{~mm}$ lateral, $3 \mathrm{~mm}$ ventral; Paxinos and Watson, 2004). Four days after the end of CUS, rats were temporarily anesthetized using isoflurane, the stylet from the outer guide cannulae removed, and an injection cannulae made from silica tubing was filled with either artificial CSF (aCSF) or the 5HT2A/C agonist (-)-2,5-dimethoxy-4-iodoamphetamine hy-

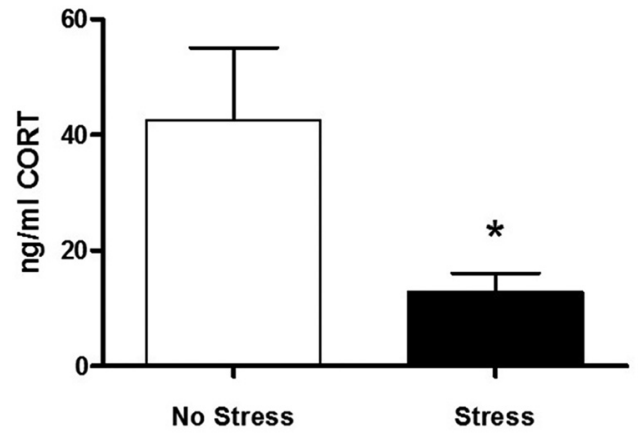

Figure 1. Basal CORT day after CUS. Graph of basal CORT measured from plasma morning after the last stressor indicate a significant decrease in CORT in the Stress group $(n=6)$ compared with the NoStress group $\left(n=5 ;{ }^{*} p<0.05\right)$.

drochloride (DOI). The injection cannula was inserted $1 \mathrm{~mm}$ past the guide cannula so that the tip was positioned in the $\mathrm{mPFC}(2.7 \mathrm{~mm}$ bregma, $0.5 \mathrm{~mm}$ lateral, $4 \mathrm{~mm}$ ventral; Paxinos and Watson, 2004). Either aCSF or $10 \mathrm{~nm}$ DOI $(0.25 \mu \mathrm{l})$ was injected into the mPOA. This dose of DOI has been shown to elicit a cardiovascular and hyperthermic response when injected into the hypothalamus (Lin et al., 1998; Bell et al., 1999).

Experimental design and statistical analysis. Data analyses were conducted using SigmaPlot 11.0 software. Comparisons between the NoStress and Stress groups were made using unpaired $t$ test to analyze basal CORT (see Fig. 1), latency and duration of immobility in the 1 month forced-swim tests (see Fig. $3 a, b$ ), and DRif TUNEL-positive cells (see Fig. 6b). Barnes maze acquisition data were analyzed using three-way ANOVA to compare stress $\times$ treatment $\times$ day and was followed by post hoc Tukey's multiple-comparisons tests. All other data were analyzed using a two-way ANOVA to compare stress $\times$ treatment groups followed by post hoc Tukey's multiple-comparisons tests. Histological sections through the DRN that had tears in the area of interest and rats having placement of tracer/DOI injection outside of the targeted area were excluded from histological analysis. All data are presented as mean \pm SEM and significance was determined at $p<0.05$.

\section{Results}

Basal CORT concentrations in plasma indicate that $21 \mathrm{~d}$ of CUS significantly decreased CORT (NoStress $=42.53 \pm 12.56 \mathrm{ng} / \mathrm{ml}$, Stress $=12.89 \pm 3.26 \mathrm{ng} / \mathrm{ml}, t(9)=2.49, p<0.034$; Fig. 1$)$.

To determine whether NMDA receptor activity during CUS played a role in stress-induced depressive-like symptoms, rats underwent the forced-swim test. NMDA receptor inhibition with MK801 treatments during CUS blocked the decrease in latency to immobility and increase in duration of immobility examined $4 \mathrm{~d}$ after CUS. There was a main effect of MK801 treatment $\left(F_{(1,20)}=\right.$ $5.76, p=0.026)$ and an interaction between MK801 and stress $\left(F_{(1,20)}=6.39, p=0.020\right)$ in the latency to immobility. Vehicle treatment during stress significantly decreased latency to immobility $(q=4.17, p=0.008)$ compared with NoStressVehicle and MK801 during stress significantly increased the latency to immobility compared with StressVehicle $(q=5.15, p=0.002$; Fig. $2 a)$. In addition, there was an interaction between MK801 and stress $\left(F_{(1,21)}=5.53, p=0.029\right)$ in the duration of immobility. Vehicle treatment during stress significantly increased duration of immobility $(q=3.59, p=0.019)$ compared with NoStressVehicle and MK801 during stress significantly decreased the duration of immobility compared with StressVehicle $(q=4.47, p=0.005$; Fig. 2b).

The forced-swim test was conducted 1 month after CUS exposure to determine whether stress exposure caused persistent changes in mood and depression-like behavior. Although no dif- 

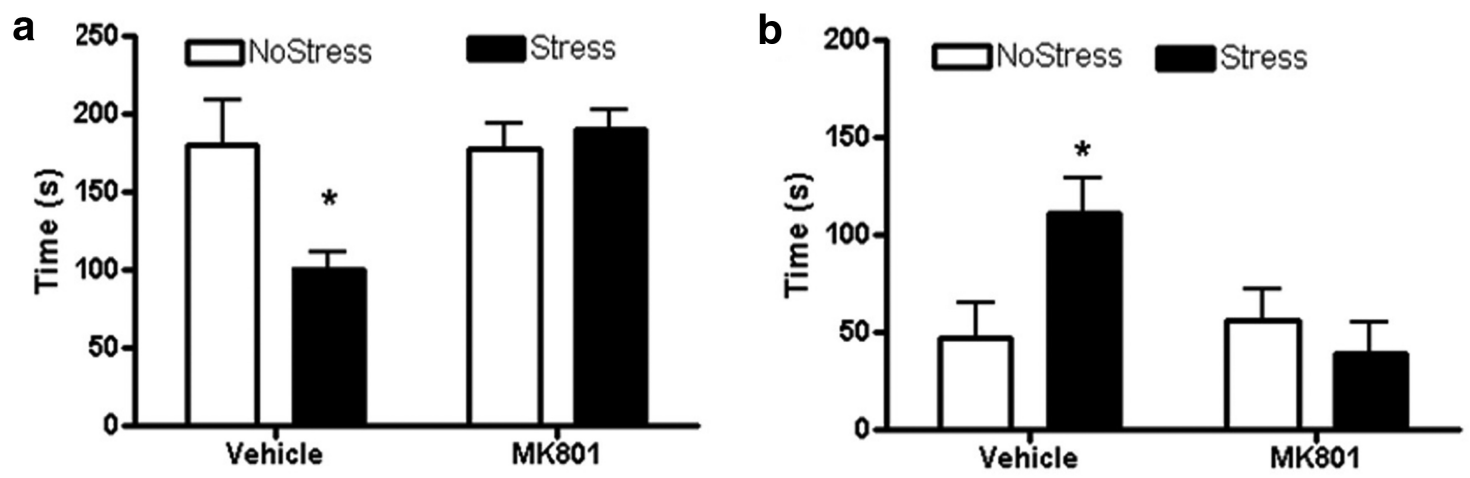

Figure 2. Forced-swim test $4 \mathrm{~d}$ after CUS. MK801 or vehicle saline was injected 15 min before each stressor. (NoStressVehicle, $n=5$; StressVehicle, $n=8$; NoStressMK801, $n=6$; and NoStressMK801, $n=7)$. $\boldsymbol{a}$, The StressVehicle group showed significantly lower latency to immobility during forced-swim test compared with all other groups $\left({ }^{*} p<0.01\right.$, StressVehicle vs all other groups). $\boldsymbol{b}$, The StressVehicle group showed significantly longer duration spent in immobile behavior during forced-swim test compared with all other groups $\left({ }^{*} p<0.05\right.$, StressVehicle vs all other groups).
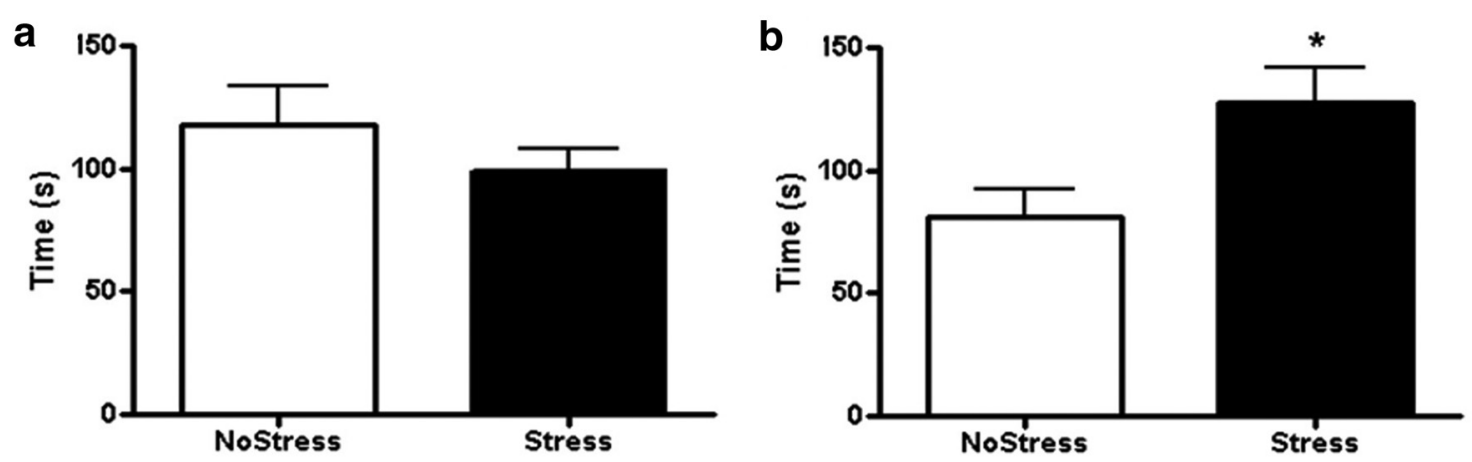

Figure 3. Forced-swim test 1 month after last CUS. $\boldsymbol{a}$, Latency to immobility during forced-swim test in the NoStress and Stress groups. (NoStress, $n=6 ;$ Stress, $n=8$ ). $\boldsymbol{b}$, Duration spent in immobile behavior during the $10 \mathrm{~min}$ forced-swim test. Stressed rats had significantly longer duration of immobility compared with the NoStress group $\left({ }^{*} p<0.05 ;\right.$ NoStress, $n=5 ;$ Stress, $\left.n=8\right)$.

ference in the latency to immobility was observed between the Stress and NoStress groups (Fig. $3 a$ ), there was a significant increase in the duration of immobility in the Stress group $(t(11)=$ 2.25, $p<0.05$; Fig. 3b).

Rats were tested in the Barnes maze to determine whether CUS exposure caused long-lasting cognitive deficits. A three-way ANOVA showed a significant main effect of stress $\left(F_{(1,223)}=4.40\right.$, $p=0.037)$ and day of acquisition training $\left(F_{(4,223)}=14.65, p<\right.$ 0.001; Fig. 4a). The Stress group had longer latencies to find the goal box compared with NoStress rats $(q=2.97, p=0.036)$. The rats exhibited longer latencies to find the goal box on day 1 compared with all other days (day 1 vs day $2: q=4.35, p=0.018$; day 1 vs day $3: q=6.44, p<0.001$; day 1 vs day $4: q=8.19, p<0.001$; day 1 vs day $5: q=9.88, p<0.001$ ).

To ascertain whether CUS caused deficits in memory recall, the latency to find the goal box after a $2 \mathrm{~d}$ break from acquisition training was recorded. Results indicate an interaction between stress and treatment $\left(F_{(1,45)}=4.08, p<0.049\right)$. Vehicle treatment during CUS significantly increased the latency to find the goal box compared with the NoStressVehicle group $(q=4.86, p=$ 0.001 ) and MK801 treatment during stress decreased the latency compared with StressVehicle $(q=3.47, p=0.018$; Fig. $4 b)$.

Perseverative behavior measured as duration spent in the quadrant that originally contained the goal box but then was removed before the test showed a main effect of stress $\left(F_{(1,45)}=\right.$ $7.11, p=0.011)$ and an interaction between stress and treatment $\left(F_{(1,45)}=4.45, p=0.040\right)$. Vehicle treatment during CUS significantly increased the duration spent in the quadrant that originally contained the goal box compared with NoStressVehicle group $(q=5.91, p<0.001)$ and MK801 treatment by itself increased perseverative behavior in the NoStress group $(q=3.14$, $p=0.031$; Fig. $4 c$ ).

Cognitive flexibility was assessed in the rats by moving the goal box from the 2:00 to the 5:00 position in the maze and latency to find the goal box in the new position was timed. A significant main effect of stress was observed $\left(F_{(1,45)}=8.72, p=\right.$ $0.005)$ with the StressVehicle rats exhibiting a longer latency to find the goal box in the new position compared with the NoStressVehicle rats $(q=3.77, p=0.011$; Fig. $4 d)$.

To analyze the effects of CUS on 5HT soma in the DRN (Fig. 5a), cells positive for NeuN and TPH were counted in the DRif and the ventromedial (DRVM), dorsomedial (DRDM), and ventrolateral/ periaqueductal gray (VL/PAG) subregions of the DRN (Fig. 5b). There was a significant main effect of stress $\left(F_{(1,50)}=6.72, p=0.012\right)$ and subregion $\left(F_{(3,50)}=114.87, p<0.001\right)$. Post hoc test indicated a significant decrease in NeuN $+\mathrm{TPH}$-positive cells to $54.8 \pm 5.6 \%$ in the DRif of the Stress group (cell counts $=9.4 \pm 0.9 ; q=4.19, p=$ $0.005)$ compared with the NoStress group (cell counts = 17.1 \pm 0.1 ). No significant differences were observed in the DRVM, DRDM, or VL/PAG between the Stress and NoStress groups (Fig. $5 c$ ).

TUNEL-positive staining was assessed in the DRN to determine whether the decrease in $\mathrm{NeuN}+\mathrm{TPH}$-positive cells is due to cell death through apoptosis (Fig. 6a). A significant increase of $286.4 \pm 56.8 \%$ in TUNEL + TPH compared with NoStress $(t(14)=2.95, p=0.010)$ was observed in the DRif $1 \mathrm{~d}$ after exposure to $17 \mathrm{~d}$ of CUS (Fig. $6 b$ ).

The role of the NMDA receptor in mediating the loss of NeuN + TPH immunoreactivity in the DRif was examined by 
a

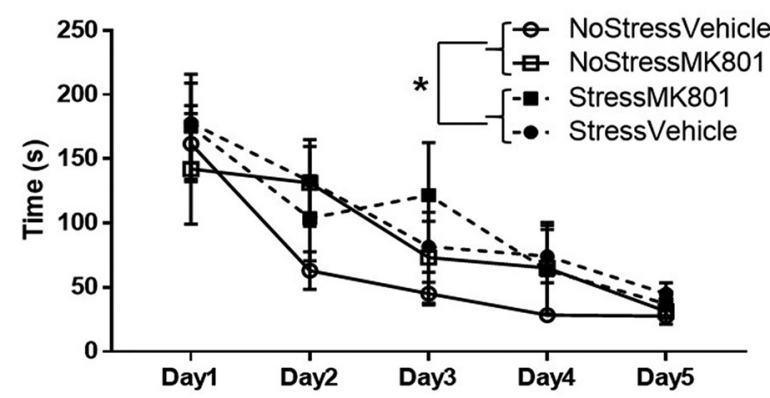

C

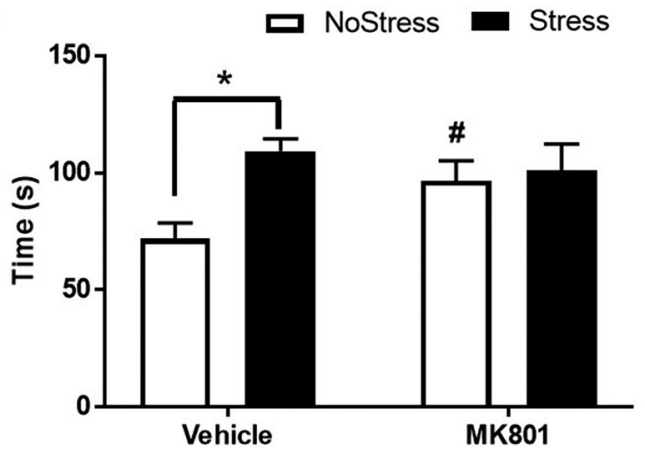

b

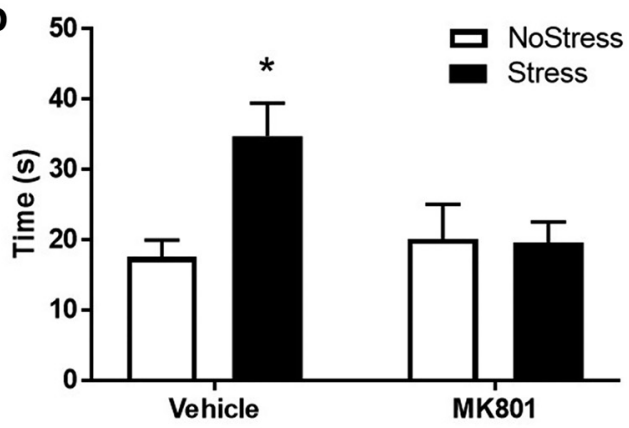

d

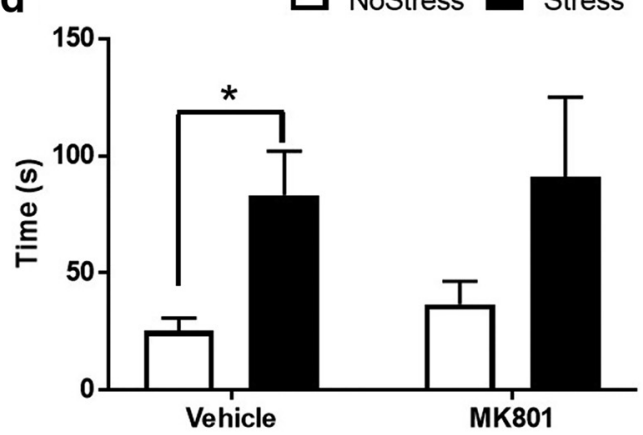

Figure 4. Barnes maze testing 1 month after CUS. (NoStressVehicle, $n=16$; StressVehicle, $n=17$; NoStressMK801, $n=8 ;$ StressMK801, $n=8$ ). $\boldsymbol{a}$, Acquisition over 5 d of training in the maze show an effect of stress. ${ }^{*} p<0.05$. $\boldsymbol{b}$, After a $2 \mathrm{~d}$ break from acquisition training, rats were tested for recall function in the maze. The StressVehicle group showed significantly longer latency to find the goal box ( ${ }^{*} p<0.05$, StressVehicle vs all other groups). $c$, Rats were tested for perseverative behavior by recording duration spent in the quadrant that usually contained the goal box in the absence of a goal box in the maze. StressVehicle rats showed significantly longer duration spent in the quadrant compared with NoStressVehicle ${ }^{*} p<0.001$, StressVehicle vs NoStressVehicle) and the NoStressMK801 group showed significantly longer duration spent in the quadrant compared with the NoStressVehicle group (\#p <0.05, NoStressMK801 vs NoStressVehicle). $\boldsymbol{d}$, Rats were tested for reversal learning by moving the goal box from its standard position to a new location on the maze and the latency to find the goal box in the new location was recorded. StressVehicle rats took significantly longer time to find the goal box compared with the NoStressVehicle group $\left({ }^{*} p<0.01\right.$, StressVehicle vs NoStressVehicle).

a

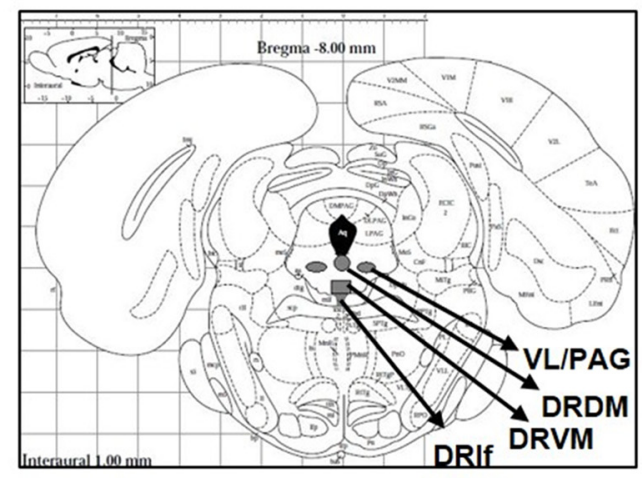

C

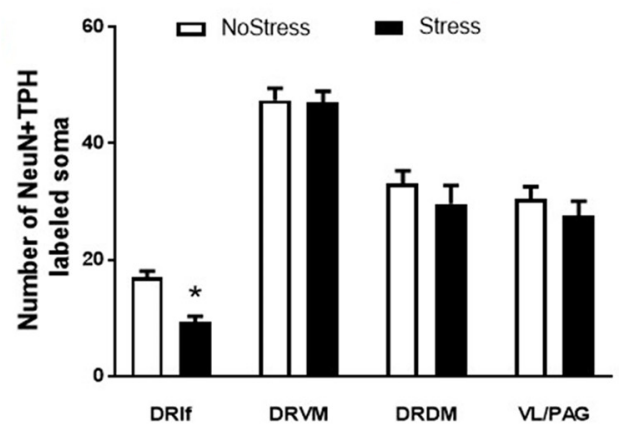

b
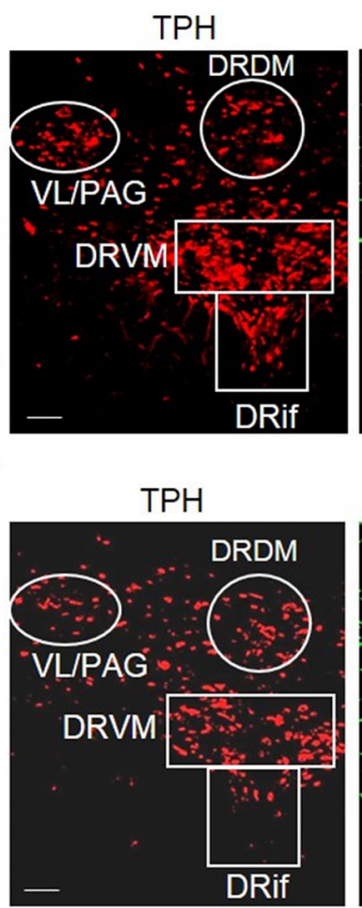

No Stress

NeuN

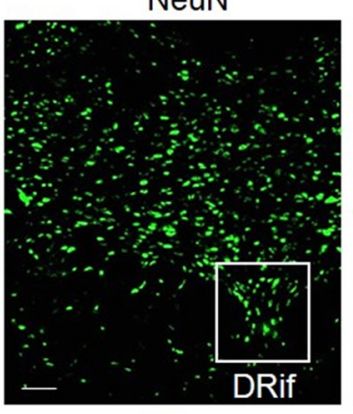

Stress

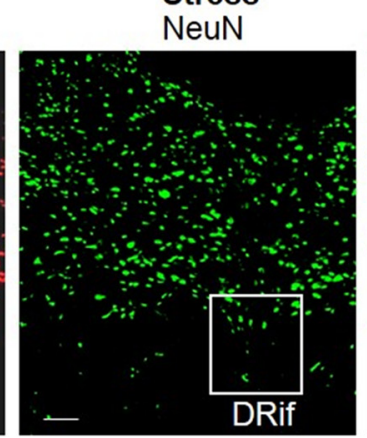

Merge

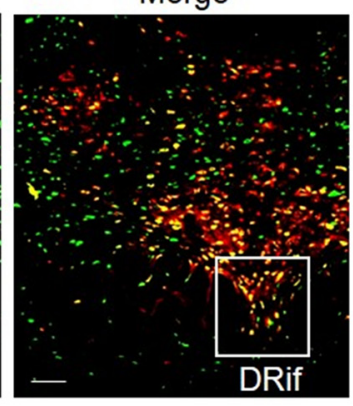

Merge

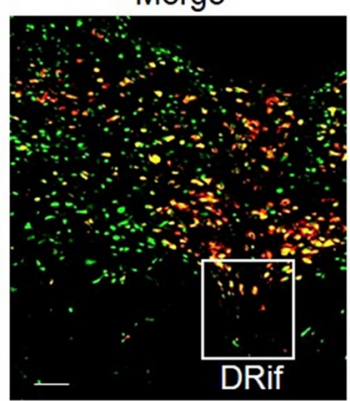

Figure 5. NeuN + TPH-positive cells in the DRN. 5HT cells in the DRN were counted in Stress and NoStress rats 1 week after CUS. (NoStressDRif, $n=8 ;$ NoStressDRVM,$n=8 ;$ NoStressDRDM $n=8$; NoStressVL/PAG, $n=8 ;$ StressDRif, $n=8 ;$ StressDRVM, $n=8 ;$ Stress DRDM, $n=5$; and StressVL/PAG, $n=5$ ). $\boldsymbol{a}$, Identification of subregions analyzed within the DRN based on the rat brain atlas (Paxinos and Watson, 2004). $\boldsymbol{b}$, Representativeimages (10× magnification) ofNeuN + TPH-positivecells intheDRN. Redindicates TPH; green, NeuN; andyellow,NeuN + TPH colocalization in NoStressandStress rats. c, Graph of NeuN + TPH-positive cells in the DRN subregions. DRif subregion shows a significant decrease in the number of NeuN + TPH cells after Stress ( $\left.{ }^{*} p<0.001\right)$. White scale line indicates $100 \mu \mathrm{m}$. 
a

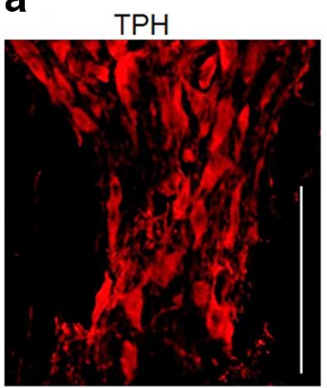

$\mathrm{TPH}$

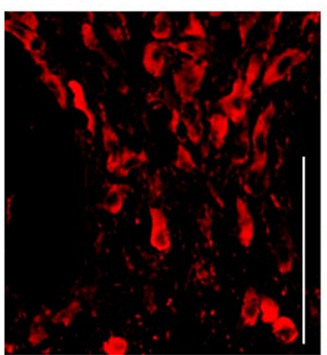

No Stress

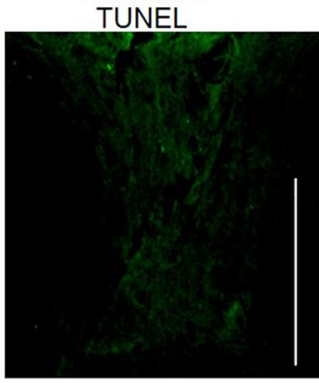

Stress

TUNEL

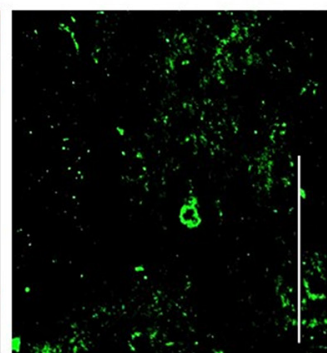

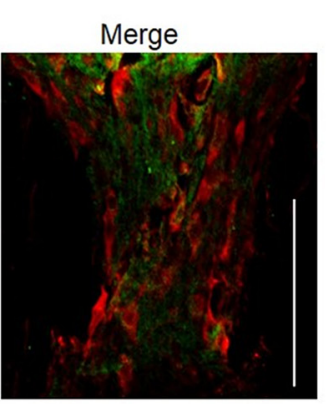

b

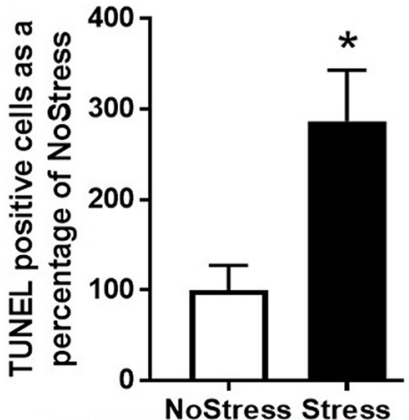

NoStress Stress

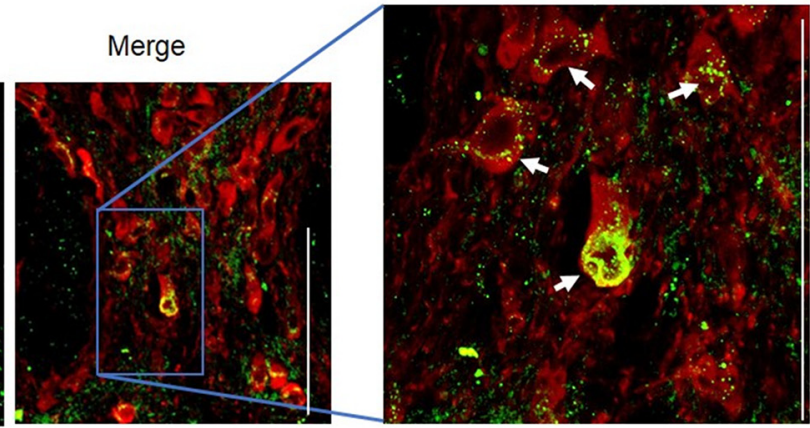

Figure 6. TUNEL-positive cells in the DRN after $17 \mathrm{~d}$ of CUS. $\boldsymbol{a}$, Top and bottom panels show representative immunofluorescence images of the DRif in the NoStress and Stress groups, respectively, of TPH immunoreactivity (red), TUNEL stain (green), and the merge (yellow). There was minimal to no distinct TUNEL staining in the NoStress group but punctate TUNEL staining surrounding the nuclei of TPH-positive cells in the Stress group. The white arrows point to TUNEL-positive cells in the DRif of the Stress group. The expanded image is $60 \times$ magnification. White line/bar, $100 \mu m$. Variations in TUNEL intensity is attributed to differences in the plane and angle of section of TUNEL-labeled soma in the DRif. $\boldsymbol{b}$, Graph of TUNEL/TPH-positive cells normalized to NoStress ( ${ }^{*} p<0.05$; NoStress, $n=8 ;$ Stress, $n=8$ ).

a
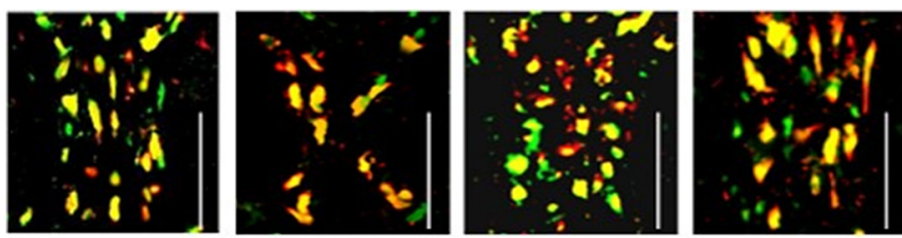

NoStressVehicle
StressVehicle

NoStressMK801 b

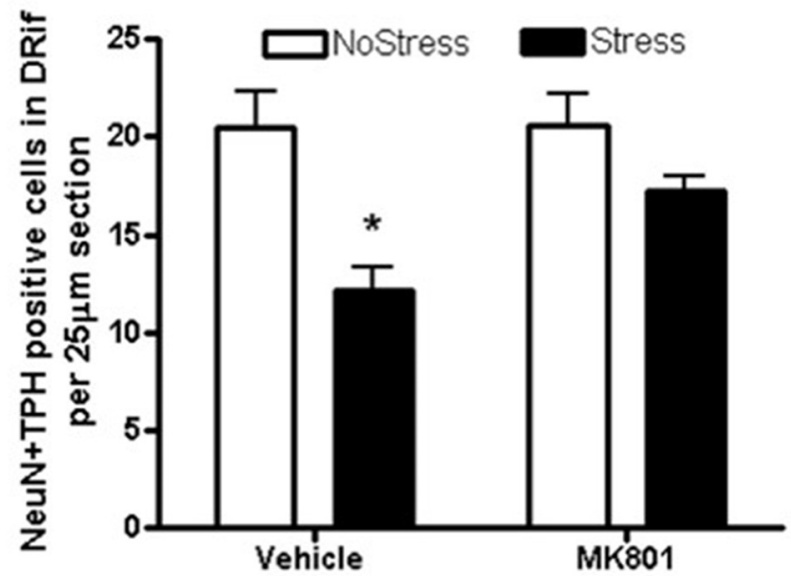

Figure 7. NeuN + TPH-positive cells in the DRif 1 week after MK801 treatment during stress. MK801 $(0.3 \mathrm{mg} / \mathrm{kg})$ or vehicle saline was injected $15 \mathrm{~min}$ before each stressor. $5 \mathrm{HT}$ cells in the DRif were counted in Stress and NoStress rats 1 week after the last stressor (NoStressVehicle, $n=6$; NoStressMK801, $n=5$; StressVehicle, $n=5$; StressMK801, $n=6$ ). $\boldsymbol{a}$, Representative images (10X magnification) of NeuN + TPH-positive cells in the DRif. Red indicates TPH; green, NeuN; yellow, NeuN + TPH colocalization. White line, $100 \mu \mathrm{m}$. $\boldsymbol{b}$, Graph of NeuN + TPH-positive cells counted in the DRif in MK801 or vehicle (saline) pretreated rats illustrates a significant decrease in StressVehicle group that is blocked by MK801 ( ${ }^{*} p<0.001$ vs NoStress). administering the NMDA receptor antagonist MK801 during CUS. DRif cells that colabeled NeuN and TPH were counted 1 week after the end of CUS (Fig. 7a). A two-way ANOVA showed a significant main effect of stress $\left(F_{(1,18)}=16.74, p<\right.$ 0.001 ; Fig. $7 b)$. Vehicle treatment during CUS significantly decreased NeuN + TPH-immunoreactive cells in the DRif $(q=5.83, p<0.001)$ and MK801 treatment during CUS significantly increased $\mathrm{NeuN}+\mathrm{TPH}$ cell counts compared with the StressVehicle group $(q=3.56, p=$ 0.022 ).

To elucidate whether CUS affected 5HT neurons that projected from the DRif to the $\mathrm{mPFC}$, the retrograde tracer TrueBlue was injected into the $\mathrm{mPFC}$ (Fig. 8a) and tracer-positive cells in the DRif were counted in rats that were pretreated with either vehicle or MK801 (Fig. 8b). Results indicated a main effect of stress $\left(F_{(1,22)}=5.58, p=0.027\right)$ and MK801 treatment $\left(F_{(1,22)}=9.21, p=\right.$ $0.06)$ and an interaction between stress and MK801 treatment $\left(F_{(1,22)}=9.21\right.$, $p=0.006$; Fig. 8c). The StressVehicle group had significantly fewer TrueBluepositive cells in the DRif $(q=4.83, p<$ 0.003) compared with NoStressVehicle and MK801 treatment during CUS significantly increased the number of TrueBlue- 


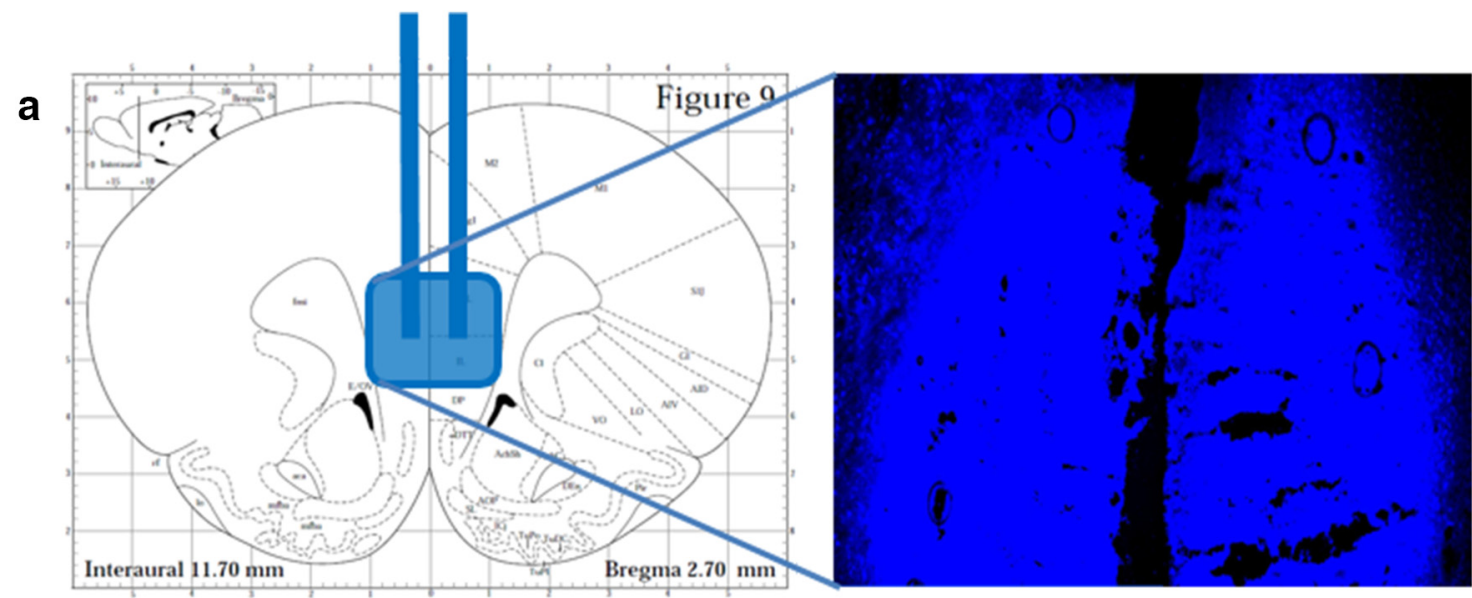

b
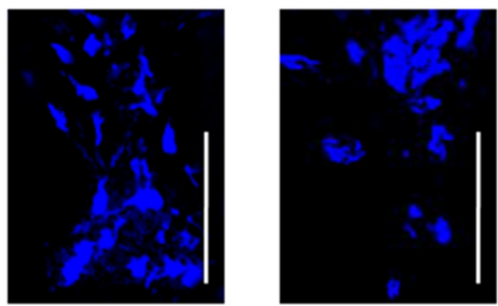

NoStressVehicle StressVehicle
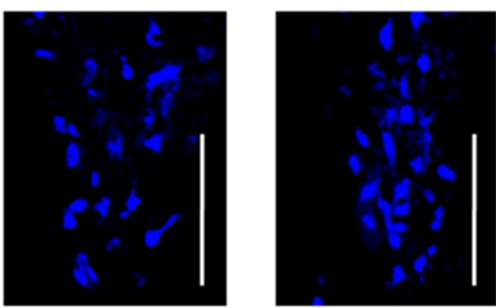

NoStressMK801 StressMK801
C

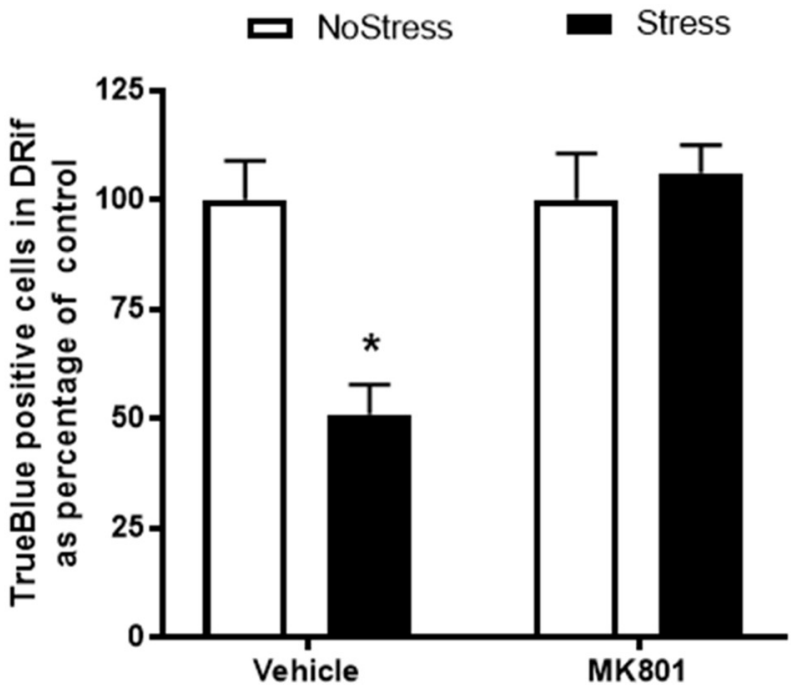

Figure 8. Retrograde tracer TrueBlue injection into the MPFC in MK801-pretreated rats. $\boldsymbol{a}$, Schematic representation of tracer injection into the $\mathrm{mPFC}$ according to the rat brain atlas (Paxinos and Watson, 2004). $\boldsymbol{b}$, Representative images of TrueBlue-positive cells in the DRif in the NoStressVehicle, StressVehicle, NoStressMK801, and StressMK801 groups. White line, $100 \mu \mathrm{m}$ (NoStressVehicle, $n=4$; StressVehicle, $n=6$; NoStressMK801, $n=8$; and StressMK801, $n=8$ ). c, Percentage of TrueBlue positive cells in the DRif in Stress and NoStress groups after intraperitoneal injection with either $1 \mathrm{ml} / \mathrm{kg}$ vehicle (saline) or $0.3 \mathrm{mg} / \mathrm{kg}$ MK801. The StressVehicle had a significantly decreased number of TrueBlue-positive cells in the DRif $\left({ }^{*} p<\right.$ 0.01 , StressVehicle vs all other groups).

positive cells counted in the DRif compared with the StressVehicle group $(q=6.49, p<0.001)$.

The 5HT2A/C agonist DOI was injected into the mPFC of rats $4 \mathrm{~d}$ after CUS and tested in the forced swim task to examine the possibility of blocking depressive behavior that was associated with decreased in 5HT innervation to the mPFC. A significant main effect of DOI treatment was observed $\left(F_{(1,24)}=16.33, p<\right.$ $0.001)$ and there was a interaction between DOI treatment and stress $\left(F_{(1,24)}=7.4, p=0.012\right)$ in the latency to immobility. aCSF treatment during stress decreased latency to immobility $(q=3.1$, $p=0.041)$ compared with NoStress-aCSF and DOI during stress significantly increased the latency to immobility compared with Stress-aCSF $(q=6.8, p<0.001$; Fig. $9 a)$. In addition, a significant main effect of DOI was observed $\left(F_{(1,25)}=8.1, p=0.009\right)$ and there was a interaction between DOI and stress $\left(F_{(1,25)}=10.1\right.$, $p=0.004)$ in the duration of immobility. Stress increased the duration of immobility ( $q=3.45, p=0.022)$ compared with NoStress-aCSF and DOI treatment during stress decreased the duration of immobility compared with stress-aCSF $(q=6.1, p<$ 0.001; Fig. 9b).

\section{Discussion}

The results show that CUS produced multiple and persistent neuroanatomical, behavioral, and neurochemical changes. Basal CORT was significantly decreased by CUS. Rats exposed to CUS exhibited long-lasting learned helplessness as indicated by shorter latency to immobility and longer durations spent immobile in the forced-swim test, all of which were blocked by MK801 treatment during CUS. Furthermore, deficits in acquisition, recall, perseveration, and reversal learning were observed. Cell death in the DRif specifically and its projections to the mPFC were associated with these behavioral changes in a manner blocked by MK801 pretreatment during CUS. In addition, the depression-like behaviors were blocked by injection of the acute $5 \mathrm{HT} 2 \mathrm{~A} / \mathrm{C}$ agonist into the mPFC before forced-swim testing.

\section{CUS and depression-like behavior}

Basal CORT was lower in rats exposed to CUS (Fig. 1). These results are consistent with low basal plasma CORT levels observed in mood disorders such as posttraumatic stress disorder and chronic fatigue 

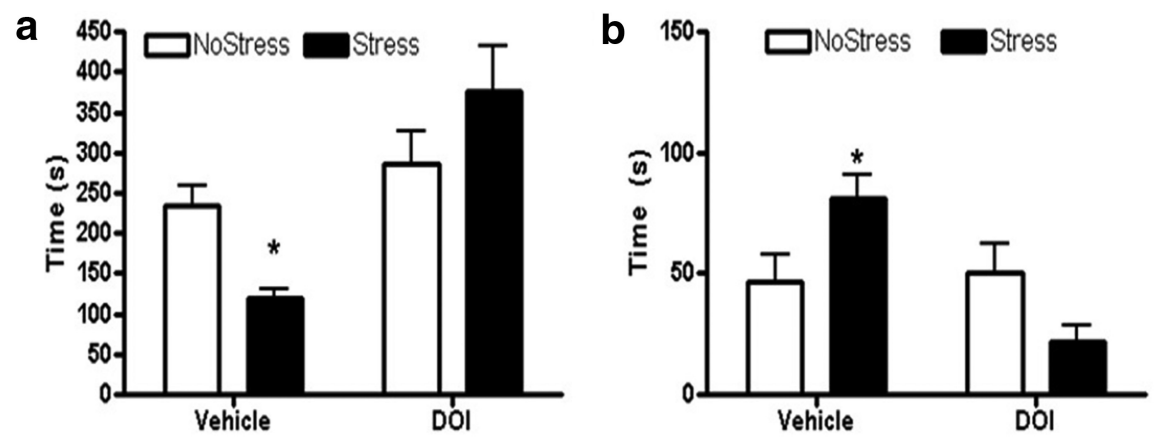

Figure 9. Forced-swim test $3 \mathrm{~d}$ after CUS. The 5HT2A/C agonist DOI or vehicle aCSF was injected bilaterally into the $\mathrm{mPFC}$ 15 min before forced-swim testing (NoStressVehicle, $n=7$; StressVehicle, $n=7$; NoStressD0I, $n=7$; and StressD0I, $n=$ 7). $\boldsymbol{a}$, The StressVehicle group showed significantly lower latency to immobility during the forced-swim test compared with all other groups ( ${ }^{*} p<0.05$, StressVehicle vs all other groups). $\boldsymbol{b}$, The StressVehicle group showed significantly longer duration spent in immobile behavior during the forced-swim test compared with all other groups $\left({ }^{*} p<0.05\right.$, StressVehicle vs all other groups).

syndrome that is comorbid with depression and cognitive dysfunction (Oquendo et al., 2003; Torres-Harding et al., 2008; Papadopoulos and Cleare, 2011). Moreover, forced-swim testing conducted $4 \mathrm{~d}$ after CUS indicated that CUS rats exhibited depression-like behavior reflected by decreased latency to immobility and increased duration of immobility (Fig. 2a,b). The longer durations of immobility persisted when measured 1 month after the termination of CUS and paralleled the findings that chronic stress increases the likelihood for development of depression long after exposure to stressful events has ceased (Hammen et al., 1992; Kessler, 1997). In contrast, there was no significant change in latency to immobility (Fig. $3 a$ ). This lack of change in latency to immobility appeared to be due to a decrease in latency to immobility in the NoStress control rats tested in forced swim at 1 month versus $3 \mathrm{~d}$ after CUS. It is possible that prior exposure to the forced-swim testing at $3 \mathrm{~d}$ after CUS could have affected performance 1 month later. In fact, a similar effect over this time span has been observed in young-adult versus middle-aged female rats (Récamier-Carballo et al., 2012). Therefore, age could interact with CUS to cause a persistent increase in duration of immobility and is consistent with long-lasting deficits in mood exhibited by patients diagnosed with depressive disorder (Hammen et al., 1992).

\section{CUS and cognition}

Persistent-stress-induced depression increases the likelihood for the development of cognitive impairments (Jorm, 2000) and can persist even after depressive behavior is no longer apparent (Reppermund et al., 2009), indicating that stress can cause long-lasting cognitive impairments. Our results show that CUS-induced impairment in acquisition was not blocked by MK801 treatment and suggest an NMDA-independent mechanism (Fig. 4a); however, MK801 blocked the stress induced deficit in recall function (Fig. $4 b$ ). This finding is consistent with the role of the PFC in long-term memory storage and retrieval (Simons and Spiers, 2003; Jo et al., 2007). In addition, exposure to stress causes dendritic atrophy in the PFC through an NMDA-receptor-dependent manner (Martin and Wellman, 2011) and may be the cause of the behavioral changes produced by CUS in the current study.

CUS rats also spent a longer time in perseverative behavior (Fig. $4 c, d$ ), as did the NoStress/MK801 group, compared with the NoStressVehicle group. This finding suggests that longterm NMDA receptor antagonism alone can cause lasting dysfunction in perseverative behavior. However, MK801 treatment during stress increased perseverative behavior similar to the
NoStressMK801 group, indicating that MK801 may have blocked the stressinduced enhancement in perseverative behavior. In contrast, MK801 treatment during CUS did not block the CUSinduced impairments in reversal learning and is consistent with the findings that NMDA receptor antagonists by themselves cause long-term deficits in reversal learning without affecting acquisition (Zajaczkowski et al., 2000).

\section{CUS and 5HT soma in the DRN}

Several studies have shown that dysregulation of $5 \mathrm{HT}$ in the MPFC causes deficits in memory formation, memory retrieval, and behavioral flexibility (Incisa della Rocchetta and Milner, 1993; Tulving et al., 1994; Runyan et al., 2004; Clarke et al., 2007). Because DRN 5HT neurons innervate the mPFC, it can be reasoned that the loss of DRN cells can affect cognitive behavior. Cell counts of the DRN 1 week after $21 \mathrm{~d}$ of stress indicate that CUS decreased the number of NeuN $+\mathrm{TPH}$-immunoreactive cells in the DRif by $\sim 40 \%$ without having any effect on cells in other subregions of the DRN (Fig. 5c). Furthermore, TUNEL was detected in the DRif cells during CUS (day 17 of CUS) indicative of existing cell soma undergoing apoptosis, unlike 1 week after CUS at a time when cell soma have already been lost (Fig. 6). The reason for the specificity of neuronal cell death in the DRif is unclear, but there are several factors that are unique to the DRif that could underlie its vulnerability. The DRif contains morphologically and electrophysiologically distinct, stress-sensitive 5HT neurons that project to the mPFC (Hale and Lowry, 2011; Kelly et al., 2011). Furthermore, the DRif neurons contain glucocorticoid (Ahima and Harlan, 1990), corticotropin releasing factor (CRF) (Lukkes et al., 2011), and AMPA/NMDA receptors (Laurie et al., 1995) that are activated by stress-induced increases in CORT, CRF innervation from the amygdala (Gray, 1993), and glutamatergic input originating from the mPFC (Commons et al., 2005), respectively. Therefore, the combination of differential sensitivity to stress (Kawahara et al., 1993; Adell et al., 1997; Lowry, 2002; Maier and Watkins, 2005; Crawford et al., 2010) due to distinct electrophysiological properties, afferents, and receptor distribution of the DRif neurons may underlie their selective vulnerability to CUS.

The presence of AMPA/NMDA receptors (Laurie et al., 1995) on DRif neurons suggests a glutamatergic component to the stress-induced damage of DRif cells (McEwen et al., 1995). Stress and the activation of glucocorticoid receptors increases calcium channel and NMDA receptor activity, potentiates glutamate release in the hippocampus, and increases cytosolic calcium concentrations to cause cell damage (Sapolsky, 1986; Landfield and Eldridge, 1994; Moghaddam et al., 1994; Bartanusz et al., 1995; Weiland et al., 1997). In fact, neuronal atrophy and cell death in the hippocampus have been attributed to stress hormones and NMDA receptor activity (Goodman et al., 1996; McEwen, 1999). Our results indicate that NMDA receptor antagonism by MK801 effectively blocked cell death in the DRif (Fig. 7) and suggest that a mechanism similar to that which occurs in the hippocampus may be responsible for the decrease in NeuN + TPH immunoreactivity in the DRif after CUS. 


\section{CUS and 5HT innervation of the mPFC}

To determine whether the projections from the DRif to the $\mathrm{MPFC}$ were disrupted by CUS, we used TrueBlue retrograde tracer injections into the MPFC and identified tracer-positive cell soma within the DRif. Figure $8 a$ illustrates that, when TrueBlue was injected into the mPFC of CUS rats, the number of tracerpositive cells in the DRif was lower compared with NoStress rats (Fig. 8c). Because TrueBlue does not require active transport, confounds relating to poor tracer uptake and transport due to damaged terminals or transporter proteins at the injection site are minimized. Therefore, a decrease in tracer-filled soma would indicate loss of DRif cells that project to the mPFC. Treatment with MK801 during CUS effectively blocked the loss of tracerpositive cells in the DRif (Fig. $8 c$ ), similar to the blockade of decreases in NeuN + TPH cells (Fig. 7), suggesting that NMDA receptor activation causes the decrease in 5HTergic cells of DRif and their innervations to the $\mathrm{mPFC}$.

The decrease in 5HT within the mPFC due to the loss of innervations from the DRif can underlie the behavioral deficits after CUS. In fact, Fontenot et al. (1995) have shown that chronic social stress in macaques caused persistent decreases mPFC 5HT and its metabolite 5HIAA. In addition, a decrease in 5HT transporter has been observed in the PFC of depressed suicide victims (Linnet et al., 1995; Austin et al., 2002) and further highlights the role of $5 \mathrm{HT}$ in modulating mood-related behavior. Interestingly, our results show that CUS-induced depression-like behavior was reversed after the development of depressive symptoms by acute bilateral injection of 5HT2A/C agonist DOI into the MPFC (Fig. 9), indicating that $5 \mathrm{HT}$ receptor stimulation in the $\mathrm{MPFC}$ by DRif-mPFC 5HT projections is critical for the expression of normal mood-related behavior.

In conclusion, the results presented in this study are the first to show that CUS is toxic to DRif cells and its innervations to the $\mathrm{mPFC}$ in a manner that is dependent upon the NMDA receptor. Furthermore, the DRif-mPFC innervations are involved differentially in depression and memory recall function, but not in acquisition of spatial learning or in behavioral flexibility. These results have important implications for understanding the effects of chronic stress and the differential functions of subregions within the dorsal raphe and help to identify the distinct neuroanatomical pathways and mechanisms that contribute to cognitive and mood dysfunctions.

\section{References}

Adell A, Casanovas JM, Artigas F (1997) Comparative study in the rat of the actions of different types of stress on the release of 5- $\mathrm{HT}$ in raphe nuclei and forebrain areas. Neuropharmacology 36:735-741. CrossRef Medline

Ahima RS, Harlan RE (1990) Charting of type II glucocorticoid receptorlike immunoreactivity in the rat central nervous system. Neuroscience 39:579-604. CrossRef Medline

Austin MC, Whitehead RE, Edgar CL, Janosky JE, Lewis DA (2002) Localized decrease in serotonin transporter-immunoreactive axons in the prefrontal cortex of depressed subjects committing suicide. Neuroscience 114:807-815. CrossRef Medline

Bambico FR, Nguyen NT, Gobbi G (2009) Decline in serotonergic firing activity and desensitization of 5-HT1A autoreceptors after chronic unpredictable stress. European Neuropsychopharmacology 19:215-228. CrossRef Medline

Barnes CA (1979) Memory deficits associated with senescence: a neurophysiological and behavioral study in the rat. J Comp Physiol Psychol 93:74-104. CrossRef Medline

Bartanusz V, Aubry JM, Pagliusi S, Jezova D, Baffi J, Kiss JZ (1995) Stressinduced changes in messenger RNA levels of N-methyl-D-aspartate and AMPA receptor subunits in selected regions of the rat hippocampus and hypothalamus. Neuroscience 66:247-252. CrossRef Medline

Bell AA, Butz BL, Alper RH (1999) Cardiovascular responses produced by microinjection of serotonin-receptor agonists into the paraventricular nucleus in conscious rats. J Cardiovasc Pharmacol 33:175-180. CrossRef Medline

Bondi CO, Rodriguez G, Gould GG, Frazer A, Morilak DA (2008) Chronic unpredictable stress induces a cognitive deficit and anxiety-like behavior in rats that is prevented by chronic antidepressant drug treatment. Neuropsychopharmacology 33:320-331. CrossRef Medline

Clarke HF, Walker SC, Dalley JW, Robbins TW, Roberts AC (2007) Cognitive inflexibility after prefrontal serotonin depletion is behaviorally and neurochemically specific. Cereb Cortex 17:18-27. Medline

Commons KG, Beck SG, Bey VW (2005) Two populations of glutamatergic axons in the rat dorsal raphe nucleus defined by the vesicular glutamate transporters 1 and 2. Eur J Neurosci 21:1577-1586. CrossRef Medline

Crawford LK, Craige CP, Beck SG (2010) Increased intrinsic excitability of lateral wing serotonin neurons of the dorsal raphe: a mechanism for selective activation in stress circuits. J Neurophysiol 103:2652-2663. CrossRef Medline

Demitrack MA, Dale JK, Straus SE, Laue L, Listwak SJ, Kruesi MJ, Chrousos GP, Gold PW (1991) Evidence for impaired activation of the hypothalamic-pituitary-adrenal axis in patients with chronic fatigue syndrome. J Clin Endocrinol Metab 73:1224-1234. CrossRef Medline

Drevets WC, Price JL, Furey ML (2008) Brain structural and functional abnormalities in mood disorders: implications for neurocircuitry models of depression. Brain Struct Funct 213:93-118. CrossRef Medline

Fontenot MB, Kaplan JR, Manuck SB, Arango V, Mann JJ (1995) Long-term effects of chronic social stress on serotonergic indices in the prefrontal cortex of adult male cynomolgus macaques. Brain Res 705:105-108. CrossRef Medline

Goodman Y, Bruce AJ, Cheng B, Mattson MP (1996) Estrogens attenuate and corticosterone exacerbates excitotoxicity, oxidative injury, and amyloid $\beta$-peptide toxicity in hippocampal neurons. J Neurochem 66:18361844. Medline

Grahn RE, Will MJ, Hammack SE, Maswood S, McQueen MB, Watkins LR, Maier SF (1999) Activation of serotonin-immunoreactive cells in the dorsal raphe nucleus in rats exposed to an uncontrollable stressor. Brain Res 826:35-43. CrossRef Medline

Gray TS (1993) Amygdaloid CRF pathways: role in autonomic, neuroendocrine, and behavioral responses to stress. Ann N Y Acad Sci 697:53-60. CrossRef Medline

Hale MW, Lowry CA (2011) Functional topography of midbrain and pontine serotonergic systems: implications for synaptic regulation of serotonergic circuits. Psychopharmacology (Berl) 213:243-264. CrossRef Medline

Hammen C, Davila J, Brown G, Ellicott A, Gitlin M (1992) Psychiatric history and stress: predictors of severity of unipolar depression. Journal of Abnormal Psychology 101:45-52. CrossRef Medline

Ikonomidou C, Stefovska V, Turski L (2000) Neuronal death enhanced by N-methyl-D-aspartate antagonists. Proc Natl Acad Sci U S A 97:1288512890. CrossRef Medline

Incisa della Rocchetta A, Milner B (1993) Strategic search and retrieval inhibition: the role of the frontal lobes. Neuropsychologia 31:503-524. CrossRef Medline

Jo YS, Park EH, Kim IH, Park SK, Kim H, Kim HT, Choi JS (2007) The medial prefrontal cortex is involved in spatial memory retrieval under partial-cue conditions. J Neurosci 27:13567-13578. CrossRef Medline

Jorm AF (2000) Is depression a risk factor for dementia or cognitive decline? A review. Gerontology 46:219-227. CrossRef Medline

Katz RJ, Roth KA, Carroll BJ (1981) Acute and chronic stress effects on open field activity in the rat: implications for a model of depression. Neurosci Biobehav Rev 5:247-251. CrossRef Medline

Kawahara H, Yoshida M, Yokoo H, Nishi M, Tanaka M (1993) Psychological stress increases serotonin release in the rat amygdala and prefrontal cortex assessed by in vivo microdialysis. Neurosci Lett 162:81-84. CrossRef Medline

Kelly KJ, Donner NC, Hale MW, Lowry CA (2011) Swim stress activates serotonergic and nonserotonergic neurons in specific subdivisions of the rat dorsal raphe nucleus in a temperature-dependent manner. Neuroscience 197:251-268. CrossRef Medline

Kessler R (1997) The effects of stressful life events on depression. Annu Rev Psychol 48:191-214.

Landfield PW, Eldridge JC (1994) The glucocorticoid hypothesis of agerelated hippocampal neurodegeneration: role of dysregulated intraneu- 
ronal calcium. Ann N Y Acad Sci 746:308-321; discussion 321-326. Medline

Laurie DJ, Putzke J, Zieglgänsberger W, Seeburg PH, Tölle TR (1995) The distribution of splice variants of the NMDARI subunit rnRNA in adult rat brain. Mol Brain Res 32:94-108. CrossRef Medline

Lin MT, Tsay HJ, Su WH, Chueh FY (1998) Changes in extracellular serotonin in rat hypothalamus affect thermoregulatory function. Am J Physiol 274:R1260-R1267. Medline

Linnet K, Koed K, Wiborg O, Gregersen N (1995) Serotonin depletion decreases serotonin transporter mRNA levels in rat brain. Brain Res 697: 251-253. CrossRef Medline

Littrell JL (2012) Taking the perspective that a depressive state reflects inflammation: implications for the use of antidepressants. Front Psychol 3:297. CrossRef Medline

Lowry CA (2002) Functional subsets of serotonergic neurones: implications for control of the hypothalamic-pituitary-adrenal axis. J Neuroendocrinol 14:911-923. CrossRef Medline

Lukkes JL, Staub DR, Dietrich A, Truitt W, Neufeld-Cohen A, Chen A, Johnson PL, Shekhar A, Lowry CA (2011) Topographical distribution of corticotropin-releasing factor type 2 receptor-like immunoreactivity in the rat dorsal raphe nucleus: co-localization with tryptophan hydroxylase. Neuroscience 183:47-63. CrossRef Medline

Maier SF, Watkins LR (2005) Stressor controllability and learned helplessness: the roles of the dorsal raphe nucleus, serotonin, and corticotropin-releasing factor. Neurosci Biobehav Rev 29:829-841. CrossRef Medline

Mann JJ (1999) Role of the serotonergic system in the pathogenesis of major depression and suicidal behavior. Neuropsychopharmacology 21.

Mann JJ, Huang YY, Underwood MD, Kassir SA, Oppenheim S, Kelly TM, Dwork AJ, Arango V (2000) A serotonin transporter gene promoter polymorphism (5-HTTLPR) and prefrontal cortical binding in major depression and suicide. Archives of General Psychiatry 57:729-738. CrossRef Medline

Marshall PS, Watson D, Steinberg P, Cornblatt B, Peterson PK, Callies A, Schenck CH (1996) An assessment of cognitive function and mood in chronic fatigue syndrome. Biol Psychiatry 39:199-206. CrossRef Medline

Martin KP, Wellman CL (2011) NMDA receptor blockade alters stressinduced dendritic remodeling in medial prefrontal cortex. Cereb Cortex 21:2366-2373. CrossRef Medline

McEwen BS (1999) Stress and hippocampal plasticity. Annu Rev Neurosci 22:105-122. CrossRef Medline

McEwen BS, Albeck D, Cameron H, Chao HM, Gould E, Hastings N, Kuroda Y, Luine V, Magariños AM, McKittrick CR (1995) Stress and the brain: a paradoxical role for adrenal steroids. Vitam Horm 51:371-402. CrossRef Medline

Moghaddam B, Bolinao ML, Stein-Behrens B, Sapolsky R (1994) Glucocorticoids mediate the stress-induced extracellular accumulation of glutamate. Brain Res 655:251-254. CrossRef Medline

Oquendo MA, Echavarria G, Galfalvy HC, Grunebaum MF, Burke A, Barrera A, Cooper TB, Malone KM, John Mann J (2003) Lower cortisol levels in depressed patients with comorbid post-traumatic stress disorder. Neuropsychopharmacology 28:591-598. CrossRef Medline

Papadopoulos AS, Cleare AJ (2011) Hypothalamic-pituitary-adrenal axis dysfunction in chronic fatigue syndrome. Nat Rev Endocrinol 8:22-32. CrossRef Medline

Papp M, Moryl E (1994) Antidepressant activity of non-competitive and competitive NMDA receptor antagonists in a chronic mild stress model of depression. Eur J Pharmacol 263:1-7. CrossRef Medline

Paul ED, Lowry CA (2013) Functional topography of serotonergic systems supports the Deakin/Graeff hypothesis of anxiety and affective disorders. J Psychopharmacol (Oxford) 27:1090-1106. CrossRef Medline

Paxinos G, Watson C (2004) The rat brain in stereotaxic coordinates, Ed 5. Burlington, MA: Elsevier Academic.

Popke EJ, Patton R, Newport GD, Rushing LG, Fogle CM, Allen RR, Pearson EC, Hammond TG, Paule MG (2002) Assessing the potential toxicity of MK-801 and remacemide: chronic exposure in juvenile rhesus monkeys. Neurotoxicol Teratol 24:193-207. CrossRef Medline

Porsolt RD, Le Pichon M, Jalfre M (1977) Depression: a new animal model sensitive to antidepressant treatments. Nature 266:730-732. CrossRef Medline

Récamier-Carballo S, Estrada-Camarena E, Reyes R, Fernández-Guasti A (2012) Synergistic effect of estradiol and fluoxetine in young adult and middle-aged female rats in two models of experimental depression. Behav Brain Res 233:351-358. CrossRef Medline

Reppermund S, Ising M, Lucae S, Zihl J (2009) Cognitive impairment in unipolar depression is persistent and non-specific: further evidence for the final common pathway disorder hypothesis. Psychol Med 39:603614. CrossRef Medline

Runyan JD, Moore AN, Dash PK (2004) A role for prefrontal cortex in memory storage for trace fear conditioning. J Neurosci 24:1288-1295. CrossRef Medline

Sapolsky RM (1986) Glucocorticoid toxicity in the hippocampus: reversal by supplementation with brain fuels. J Neurosci 6:2240-2244. Medline

Simons JS, Spiers HJ (2003) Prefrontal and medial temporal lobe interactions in long-term memory. Nat Rev Neurosci 4:637-648. CrossRef Medline

Soiza-Reilly M, Commons KG (2011) Glutamatergic drive of the dorsal raphe nucleus. J Chem Neuroanat 41:247-255. CrossRef Medline

Torres-Harding S, Sorenson M, Jason L, Maher K, Fletcher MA, Reynolds N, Brown M (2008) The associations between basal salivary cortisol and illness symptomatology in chronic fatigue syndrome. J Appl Biobehav Res 13:157-180. CrossRef Medline

Tulving E, Kapur S, Markowitsch HJ, Craik FI, Habib R, Houle S (1994) Neuroanatomical correlates of retrieval in episodic memory: auditory sentence recognition. Proc Natl Acad Sci U S A 91:2012-2015. CrossRef Medline

Valentino RJ, Lucki I, Van Bockstaele E (2010) Corticotropin-releasing factor in the dorsal raphe nucleus: Linking stress coping and addiction. Brain Res 1314:29-37. CrossRef Medline

van Riel VE, Meijer OC, Steenbergen PJ, Joëls M (2003) Chronic unpredictable stress causes attenuation of serotonin responses in cornu ammonis 1 pyramidal neurons. Neuroscience 120:649-658. CrossRef Medline

Weiland NG, Orchinik M, Tanapat P (1997) Chronic corticosterone treatment induces parallel changes in N-methyl-D-aspartate receptor subunit messenger RNA levels and antagonist binding sites in the hippocampus. Neuroscience 78:653-662. CrossRef Medline

Willner P, Muscat R, Papp M (1992) Chronic mild stress-induced anhedonia: a realistic animal model of depression. Neurosci Biobehav Rev 16: 525-534. CrossRef Medline

Zajaczkowski W, Hetman M, Nikolaev E, Quack G, Danysz W, Kaczmarek L (2000) Behavioural evaluation of long-term neurotoxic effects of NMDA receptor antagonists. Neurotox Res 1:299-310. Medline 